\section{6 OPEN ACCESS}

\title{
Risk factors for community-acquired pneumonia in adults in Europe: a literature review
}

\author{
Antoni Torres, ${ }^{1}$ Willy E Peetermans, ${ }^{2}$ Giovanni Viegi, ${ }^{3,4}$ Francesco Blasi ${ }^{5}$
}

- Additional material is published online only. To view please visit the journal online (http://dx.doi.org/10.1136/ thoraxjnl-2013-204282).

${ }^{1}$ Servei de Pneumologia, Hospital Clínic de Barcelona, Institut d'Investigacions Biomèdiques Auqust Pi i Sunyer (IDIBAPS), CIBER de Enfermedades Respiratorias (CIBERes), University of Barcelona, Barcelona, Spain ${ }^{2}$ Department of Internal Medicine, University Hospital, KU Leuven, Leuven, Belgium ${ }^{3}$ CNR Institute of Clinical Physiology, Pisa, Italy ${ }^{4}$ CNR Institute of Biomedicine and Molecular Immunology,

Palermo, Italy

${ }^{5}$ Department of

Pathophysiology and Transplantation, University of Milan, IRCCS Fondazione Ca Granda Ospedale Maggiore, Milan, Italy

\section{Correspondence to} Professor Antoni Torres, Servei de Pneumologia, Hospital Clínic de Barcelona, Institut d'Investigacions Biomèdiques August Pi i Sunyer (IDIBAPS), CIBER de Enfermedades Respiratorias (CIBERes), University of Barcelona, 08036 Barcelona, Spain ATORRES@clinic.ub.es

Received 1 August 2013 Accepted 11 August 2013

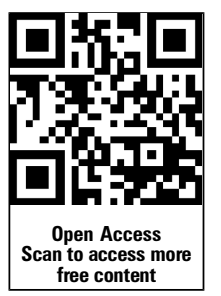

To cite: Torres $A$, Peetermans WE, Viegi $G$, et al. Thorax 2013;68:1057-1065.

\section{ABSTRACT}

Background Community-acquired pneumonia (CAP) causes considerable morbidity and mortality in adults, particularly in the elderly.

Methods Structured searches of PubMed were conducted to identify up-to-date information on the incidence of CAP in adults in Europe, as well as data on lifestyle and medical risk factors for CAP.

Results The overall annual incidence of CAP in adults ranged between 1.07 to 1.2 per 1000 person-years and 1.54 to 1.7 per 1000 population and increased with age (14 per 1000 person-years in adults aged $\geq 65$ years). Incidence was also higher in men than in women and in patients with chronic respiratory disease or HIV infection. Lifestyle factors associated with an increased risk of CAP included smoking, alcohol abuse, being underweight, having regular contact with children and poor dental hygiene. The presence of comorbid conditions, including chronic respiratory and cardiovascular diseases, cerebrovascular disease, Parkinson's disease, epilepsy, dementia, dysphagia, HIV or chronic renal or liver disease all increased the risk of CAP by twofold to fourfold.

Conclusion A range of lifestyle factors and underlying medical conditions are associated with an increased risk of CAP in European adults. Understanding of the types of individual at greatest risk of CAP can help to ensure that interventions to reduce the risk of infection and burden of disease are targeted appropriately.

\section{INTRODUCTION}

Community-acquired pneumonia (CAP) is a cause of considerable morbidity and mortality in adults in developed countries, leading to high rates of hospitalisations, especially in the elderly. ${ }^{1}{ }^{2}$ The 2010 Global Burden of Disease Study reported that lower respiratory tract infections, including pneumonia, are the fourth most common cause of death globally, exceeded only by ischaemic heart disease, strokes and chronic obstructive pulmonary disease (COPD), and they are the second most frequent reason for years of life lost. ${ }^{3}$ Within Europe, CAP is the leading cause of death due to infection, ${ }^{2}$ with approximately $90 \%$ of deaths due to pneumonia occurring in people aged $>65$ years. ${ }^{4}$ Pneumonia places a considerable burden on healthcare resources and society, with associated annual costs in Europe estimated at approximately $€ 10$ billion, mainly due to hospitalisation and lost working days. ${ }^{5}$

Several risk factors for CAP are recognised, including age $>65$ years, ${ }^{1}{ }^{6} \quad 7$ smoking, ${ }^{6}$ alcoholism, ${ }^{7}$ immunosuppressive conditions, ${ }^{7}$ and conditions such as $\mathrm{COPD},{ }^{8}$ cardiovascular disease, cerebrovascular disease, chronic liver or renal disease, diabetes mellitus and dementia. ${ }^{9}$ Although many European studies have reported on the incidence of CAP and associated risk factors, no comprehensive overviews of these data are currently available. This literature review was conducted to generate up-to-date information on the incidence of CAP in adults in Europe, and of the risk factors for contracting CAP. A secondary objective was to collect data on the rates of comorbidities in patients with CAP.

\section{METHODS}

The PubMed database was searched using the following search string: pneumonia AND English AND 2005/01/01-2012/07/31 AND risk NOT clinical trial, phase i OR clinical trial, phase ii OR clinical trial, phase iii OR controlled clinical trial OR randomised controlled trial $\mathrm{OR}$ case reports $\mathrm{OR}$ practice guideline OR editorial OR review OR cost OR cost effectiveness OR efficacy OR immunogenicity OR economic OR nosocomial. Additional searches used the same search string, but replaced 'risk' with either 'comorbidity' or 'co-morbidity'.

Papers were included if they reported observational studies performed in Western European countries (Austria, Belgium, Denmark, Finland, France, Germany, Greece, Ireland, Italy, The Netherlands, Norway, Portugal, Spain, Sweden, Switzerland, UK) and presented data from individuals aged $>15$ years on any of the following: incidence of CAP in at-risk individuals, defined as those with underlying risk factors for contracting CAP (table 1); risk factors for CAP; comorbidities in patients with CAP; pharmacotherapeutic agents associated with an increase or decrease in the risk of CAP; pathogens identified in patients with CAP. Studies that focused on nosocomial or healthcare acquired pneumonia were excluded.

Included papers were reviewed in full and data on the study setting and methodology, characteristics of the study population, incidence of CAP, risk factors for CAP (ORs or relative risks (RRs), and 95\% CIs) reported in case-control studies, and observational data on rates of comorbidities, associated pharmacotherapies and pathogens were collected. If more than one paper reported different aspects of the same study, all relevant papers were included. Where the same data were reported in more than one paper, the earliest published paper was selected.

Analysis of the included papers was descriptive and no meta-analyses of data were performed. Unless otherwise stated, all data are reported as OR (95\% CI) or RR $(95 \% \mathrm{CI})$.

\section{RESULTS}

\section{Included studies}

Of the 3330 references identified, 3240 were excluded on the basis of the title or abstract. The 
Table 1 Risk categories for community-acquired pneumonia included in the review

\begin{tabular}{ll}
\hline Immunocompetent at risk & Immunocompromised at risk \\
\hline Age & Immunosuppression \\
Lifestyle & - Autoimmune diseases receiving steroid or immunosuppressive therapy or biological therapy \\
- Alcoholism & - Cancer with immunosuppressive treatment \\
- Smoking & - Waiting list for solid-organ transplantation (with or without immunosuppressive treatment) \\
Underlying diseases & - Other immunosuppression \\
- Chronic heart disease & - Asplenia/splenic dysfunction \\
- Chronic renal disease & - Primary immunodeficiencies \\
- Chronic liver disease & HIV \\
- Chronic respiratory disease & \\
- Metabolic disease & \\
- CNS disease & \\
Prior IPD & \\
Previous pneumonia & \\
Other & \\
- Aspiration & \\
- Concomitant treatment & \\
\hline CNS, central nervous system; IPD invasive pneumococcal disease.
\end{tabular}

authors identified one additional reference ${ }^{10}$ that did not include the terms 'risk' or 'co-morbidity'/'comorbidity' in the title or abstract and was therefore not identified in the PubMed searches. However, it satisfied the other inclusion criteria. Final screening of the full papers identified 61 references meeting the inclusion and exclusion criteria, of which one paper $^{11}$ was later excluded due to data discrepancies that we were unable to resolve by correspondence with the author (figure 1).

Of the 60 publications, a majority (34) focused on hospitalised patients. Included studies were from Denmark $(n=7)$, France $(n=5), \quad$ Germany $(n=5), \quad$ Greece $(n=1)$, Italy $(n=4)$, The Netherlands $(n=3)$, Spain $(n=23)$ and the UK $(n=12)$. Study designs and populations are summarised in online supplementary table S1. Most studies included adults of all ages. However, five studies considered only patients aged $\geq 65$ years, ${ }^{12-16}$ two included patients aged 50-65 years, ${ }^{17} 18$ two included patients aged $\geq 45$ years $^{19} 20$ and single studies included patients aged $\geq 30$ years, ${ }^{21} \geq 40$ years $^{22}$ or $16-40$ years. $^{23}$ Six studies included only patients infected with HIV. ${ }^{24-29}$
Most studies included patients with pneumonia of any aetiology, but six were performed in patients with pneumonia due to a specified bacterial agent: four studies in patients with Legionella pneumophila infection, ${ }^{30-33}$ and one each in patients with Haemophilus influenzae ${ }^{34}$ or Gram-negative bacteria ${ }^{35}$ infections.

\section{Incidence of CAP}

The incidence of CAP was reported in 16 studies, from Denmark $(\mathrm{n}=2),{ }^{17} 18$ France $(\mathrm{n}=3),{ }^{24} 2629$ Germany $(\mathrm{n}=1),{ }^{36}$ Italy $(\mathrm{n}=2),{ }^{27} 37$ Spain $(\mathrm{n}=5)^{16} 25 \quad 38-40$ and the UK $(\mathrm{n}=3) .{ }^{19} 4142$ Data are summarised in table 2, with more details available in online supplementary table S2.

Differences in study populations and measures used for incidence rates make it difficult to make direct comparisons across studies. Nevertheless, several trends were apparent. The overall annual incidence of CAP in adults ranged between 1.07 to 1.2 per 1000 person-years and 1.54 to 1.7 per 1000 population $^{37384243}$ (table 2). Rates of hospitalisation for CAP
Figure 1 Summary of the study selection procedure. CAP, community acquired pneumonia. * One study did not include the terms 'risk' or 'co-morbidity'/' comorbidity' in either the title or abstract and so was not identified in the PubMed searches; however, 'risk factors' was included in the list of MeSH terms for the article.

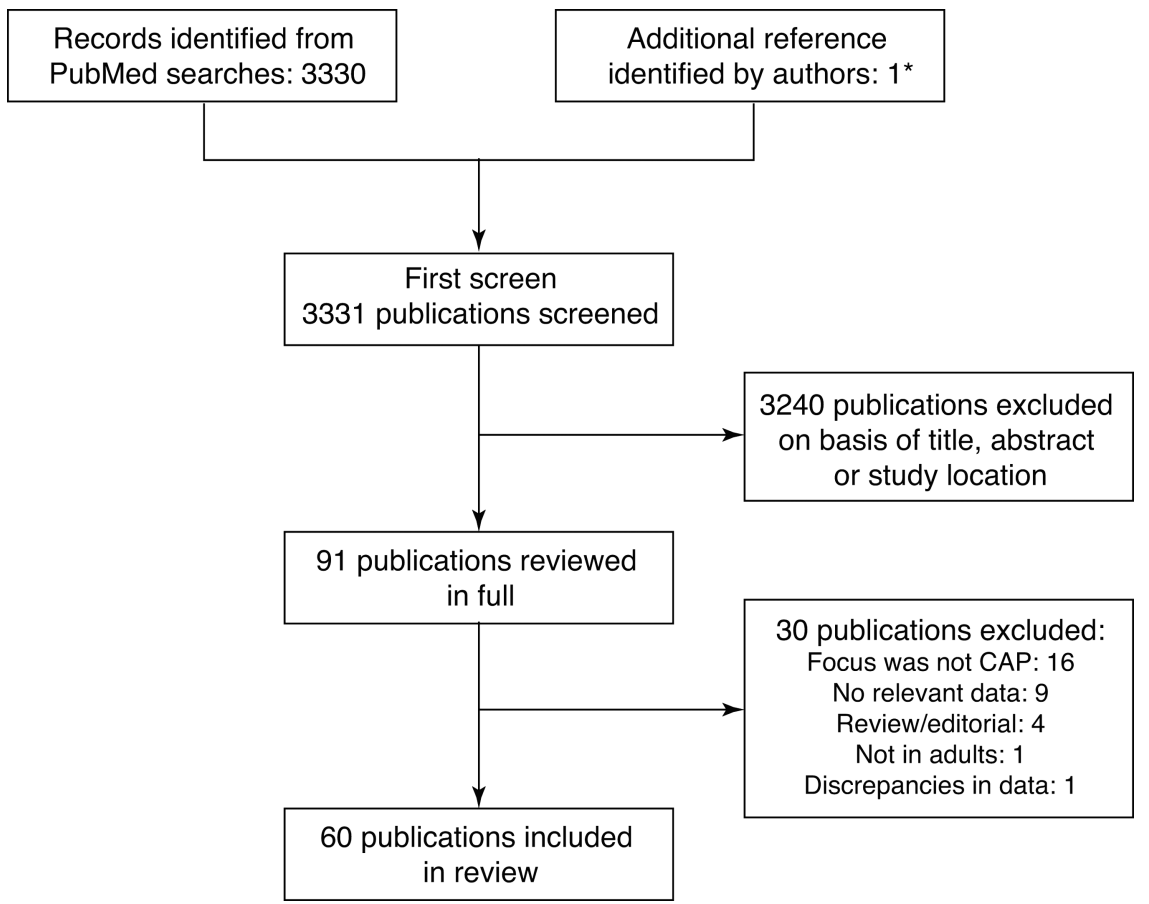


Table 2 Incidence of community-acquired pneumonia (CAP) in adults in Europe

\begin{tabular}{|c|c|c|c|}
\hline Study & Country; region & Study period & CAP incidence $(95 \% \mathrm{Cl})$ \\
\hline \multicolumn{4}{|l|}{ Overall population } \\
\hline Almirall et $a \beta^{38}$ & Spain; east coast & 1 November 1999-30 November 2000 & $\begin{array}{l}\text { Per } 1000 \text { population }>14 \text { years: } \\
1.54\end{array}$ \\
\hline Gutierrez et $a l^{39}$ & Spain; Alicante & 15 October 1999-14 October 2001 & $\begin{array}{l}\text { Per } 1000 \text { person-years: } \\
\text { Overall, } 1.230 \\
\text { Men, } 1.556 \\
\text { Women, } 0.911\end{array}$ \\
\hline Rodriguez et al ${ }^{42}$ & UK; national & 1 January 2000-31 December 2005 & $\begin{array}{l}\text { Primary care patients, per } 1000 \text { person-years: } \\
\text { Overall, } 1.07 \text { ( } 1.04 \text { to } 1.09) \\
\text { Women, } 0.93(0.89 \text { to } 0.96) \\
\text { Men, } 1.22(1.18 \text { to } 1.26)\end{array}$ \\
\hline Viegi et $a \beta^{37 *}$ & Italy; national & 15 February 1999-14 February 2000 & $\begin{array}{l}\text { Annual incidence per } 1000 \text { population: } \\
\text { Overall, } 1.703 \\
\text { Males, } 1.692 \\
\text { Females, } 1.713\end{array}$ \\
\hline Vila-Corcoles et $a l^{16}$ & Spain; Tarragona & 1 January 2002-30 April 2005 & $\begin{array}{l}\text { Age } \geq 65 \text { years, per } 1000 \text { person-years: } \\
\text { Overall, } 14.0(12.7 \text { to } 15.3) \\
\text { Men, } 19.2(17.1 \text { to } 21.6) \\
\text { Women, } 10.0 \text { ( } 8.6 \text { to } 11.5)\end{array}$ \\
\hline \multicolumn{4}{|l|}{ Hospitalisation for CAP } \\
\hline Bewick et $a /^{41}$ & UK; Nottingham & September 2008-September 2010 & Per 1000 population $\geq 16$ years: Overall, 1.097 \\
\hline Ewig et al ${ }^{\beta 6}$ & Germany; national & 2005 and 2006 & $\begin{array}{l}\text { Per } 1000 \text { population/year } \geq 18 \text { years: } \\
2005,2.75 \\
2006,2.96 \\
\text { Mean incidence: } \\
\text { Men, } 3.21 \\
\text { Women, } 2.52\end{array}$ \\
\hline Kornum et $a l^{17}$ & Denmark; Copenhagen and Aarhus & December 1993-April 2008 & $\begin{array}{l}\text { Per } 1000 \text { person-years, }>50 \text { years: } \\
\text { Men, } 4.2 \\
\text { Women, } 3.4\end{array}$ \\
\hline Kornum et $a l^{18}$ & Denmark; Copenhagen and Aarhus & December 1993-April 2008 & $\begin{array}{l}\text { Per } 1000 \text { person-years, }>50 \text { years: } \\
\text { Men, } 4.25 \\
\text { Women, } 3.28\end{array}$ \\
\hline \multicolumn{4}{|l|}{ Patients with COPD } \\
\hline Müllerova et $a l^{19}$ & UK; England and Wales & 1 January 1996-31 December 2005 & $\begin{array}{l}\text { Per } 1000 \text { patient-years: } \\
\text { Overall, } 22.4 \text { (21.7 to } 23.2) \\
\text { Women, } 21.4(20.4 \text { to } 22.5) \\
\text { Men, } 23.1 \text { ( } 22.1 \text { to } 24.2)\end{array}$ \\
\hline \multicolumn{4}{|c|}{ Immunocompromised individuals } \\
\hline Perez-Sola et $a{ }^{40} \dagger$ & Spain; national & February 2000-January 2006 & $\begin{array}{l}\text { Patients with rheumatic diseases treated with TNF } \\
\text { antagonists, per } 1000 \text { patient-years: } \\
5.97 \text { (4.87 to } 7.25)\end{array}$ \\
\hline \multicolumn{4}{|l|}{ HIV-infected individuals } \\
\hline Bénard et $a l^{24}$ & France; Aquitaine & 2000-2007 & $\begin{array}{l}\text { Per } 1000 \text { patient-years: } \\
\text { Overall: } 12.0 \text { (9.9 to } 14.0)\end{array}$ \\
\hline Curran et $a l^{25}$ & Spain; Barcelona & January 2000-December 2005 & $\begin{array}{l}\text { Cases/1000 patients/year: } \\
2000,30.90 \\
2001,31.80 \\
2002,25.70 \\
2003,21.90 \\
2004,20.50 \\
2005,24.00\end{array}$ \\
\hline Le Moing et $\mathrm{al}^{26}$ & France; national & May 1997-December 2001 & $\begin{array}{l}\text { Hospitalisation for first episode of bacterial pneumonia in protease } \\
\text { inhibitor-treated patients: } \\
8 / 1000 \text { patient-years (3-13) }\end{array}$ \\
\hline Madeddu et $a l^{27} \ddagger$ & Italy; northern Sardinia & January 1999-December 2004 & $\begin{array}{l}\text { Per } 1000 \text { inpatients/year: } \\
1999,177 \\
2004,280\end{array}$ \\
\hline Saindou et a ${ }^{29}$ & France; Lyon & 1993-2004 & $\begin{array}{l}\text { Pneumococcal pneumonia, per } 1000 \text { patient-years: } \\
\text { Cohort followed 1993-1 July } 1996 \text { (pre-HAART), } 10.6 \text { (5.4 to 15.7) } \\
\text { Cohort followed before } 1 \text { July } 1996-2004 \text { (pre-HAART and } \\
\text { HAART era), } 1.5 \text { ( } 0.9 \text { to } 2.1 \text { ) } \\
\text { Cohort followed } 1 \text { July 1996-2004 (HAART era), } 2.5 \text { (1.4 to 3.6) }\end{array}$ \\
\hline
\end{tabular}


were typically higher than overall incidence rates; for example, a German study ${ }^{36}$ reported rates of 2.75 and 2.96 per 1000 population/year aged $\geq 18$ years in 2005 and 2006 , respectively (table 2). Overall CAP incidence and hospitalisation for CAP were higher in men than in women. The overall incidence per 1000 person-years in a UK study was 1.22 (1.18 to 1.26$)$ in men compared with 0.93 (0.89 to 0.96$)$ in women, ${ }^{42}$ whereas a study in Denmark in men and women aged $>50$ years reported rates of hospitalisation for pneumonia per 1000 person-years of 4.2 in men and 3.4 in women. ${ }^{17}$

The incidence of CAP increased with age and with the presence of comorbidities (see online supplementary table S2). Among individuals aged $\geq 65$ years in Spain, the incidence per 1000 person-years was 14.0 (12.7 to 15.3$).{ }^{16}$ A study of patients with COPD reported the highest overall incidence of 22.4 (21.7 to 23.2) per 1000 person-years, with rates of 23.1 (22.1 to 24.2$)$ and 21.4 (20.4 to 22.5$)$ in men and women, respectively. ${ }^{19}$

High incidence rates were also reported in immunocompromised patients (table 2). Among patients with rheumatic diseases in Spain treated with tumour necrosis factor antagonists, the incidence per 1000 patient-years was 5.97 (4.87 to 7.25$){ }^{40}$ The incidence in patients with HIV in France, was 12.0 (9.9 to 14.0) per 1000 patient-years. ${ }^{24}$ However, highly active antiretroviral therapy (HAART) appears to reduce the risk of CAP, with another French study reporting a reduction from 10.6 (5.4 to 15.7) per 1000 patient-years in the pre-HAART era to 2.5 (1.4 to 3.6$)$ in the post-HAART era. ${ }^{29}$

\section{Lifestyle factors and risk of CAP}

The potential association between lifestyle factors and the risk of CAP was investigated in 12 case-control studies, performed in France $(n=1),{ }^{30}$ Germany $(n=1),{ }^{44}$ The Netherlands $(n=1),{ }^{23} 45$ Spain $(n=2)^{12} 38$ and the UK $(n=7) .{ }^{19-22} 424647$ Study details are summarised in online supplementary table S3.

There was consistent evidence that smoking was associated with an increased risk of CAP. ${ }^{19-23} 38424647$ Compared with non-smokers (OR 1.00), the risk of CAP was increased in current smokers (crude ORs: 1.37 (1.14 to 1.64$)$ to 1.81 (1.53 to 2.15 ); adjusted ORs: 0.99 (0.86 to 1.14$)$ to 2.00 (1.20 to 3.36)) and former smokers (crude ORs: 1.34 (1.11 to 1.62) to 1.40 (1.17 to 1.68$)$; adjusted OR: 1.04 (0.90 to 1.2$)$ ).

Compared with individuals who consumed no alcohol (OR 1.00), consumption of $\leq 40 \mathrm{~g}$ alcohol daily appeared to protect against CAP (21-40 g/day, crude ORs: 0.53 (0.22 to 1.25$)$ and $0.88(0.63$ to 1.22$)) .{ }^{23}{ }^{38}$ However, the risk increased in individuals with higher consumption $(>41 \mathrm{~g} /$ day, crude OR: 1.59 $(0.59 \text { to } 4.25)^{23}$; >80 g/day, crude OR: $2.34(1.13 \text { to } 4.85)^{38}$ ) or with a history of alcohol abuse/alcoholism (crude ORs: 1.85 $(1.19 \text { to } 2.88)^{21}$ and $\left.1.62(0.91 \text { to } 2.91)^{47}\right)$.

Being underweight was generally associated with an increased risk of CAP (crude ORs: 1.04 (0.57 to 1.89$)$ to 2.20 (1.57 to $3.09)^{23} 384447$ ) compared with normal bodyweight (OR 1.00). A reduced risk was seen in individuals classified as overweight (crude ORs: 0.6 (0.5 to 0.7) to $0.89(0.72 \text { to } 1.09)^{2123384447}$; adjusted ORs: $0.6(0.5 \text { to } 0.7)^{44}$ and $\left.0.78(0.67 \text { to } 0.90)^{19}\right)$, whereas those classified as obese had either a lower risk (crude ORs: 0.66 (0.58 to 0.75$)$ to $0.81(0.66 \text { to } 0.99)^{2138} 44 \quad 47$; adjusted ORs: $0.7(0.5 \text { to } 0.9)^{44}$ and $\left.0.71(0.60 \text { to } 0.85)^{19}\right)$ or the same risk (crude OR $1.04(0.57 \text { to } 1.89)^{23}$ ) as those of normal weight.

Household arrangements were also associated with the risk of CAP. Living in a household of over 10 people was associated with a crude OR of 2.20 (1.21 to 4.00$).{ }^{38}$ Regular contacts with children also increased the risk of CAP (crude OR: $1.48(1.26$ to 1.75$)^{38}$ ). Two studies found that having children in the household increased the adjusted OR from 1.00 for 'no children' to $3.2(1.5 \text { to } 7.0)^{44}$ or 3.41 (1.57 to 7.41$)^{23}$ for three or more children. There was no clear evidence regarding the influence of contact with pets; one study demonstrated an increased risk of CAP (crude OR 1.37 (1.18 to 1.60$)^{38}$ ), whereas a study in young adults (aged 16-40 years) found a decreased risk (crude OR $0.85(0.58 \text { to } 1.24)^{23}$ ).

Higher levels of education were associated with a lower risk of CAP. ${ }^{23} 3844$ Compared with individuals with a low level of education (OR 1.00), risk declined in those with an intermediate (secondary; crude ORs: 0.69 (0.41 to 1.19$)$ to 0.86 (0.72 to 1.01)) or high level (university; crude ORs: 0.67 (0.41 to 1.10 ) to $0.78(0.64$ to 0.96$)){ }^{23} 38$ In another study, individuals with $\geq 12$ years of education had a lower risk of CAP (adjusted OR 0.8 (0.6 to 1.1$))$ compared with those who had $\leq 9$ years of education (OR 1.00). ${ }^{44}$

Two studies found that visiting the dentist was associated with a decreased risk of CAP (in the past month, crude OR 0.71 $(0.55 \text { to } 0.92)^{38}$; in the past year, OR $\left.0.59(0.34 \text { to } 1.04)^{23}\right)$. In contrast, one study found that frequent visits to the general practitioner in the previous year were associated with a substantial increase in the risk of CAP (1-4 visits, OR $1.00 ; \geq 30$ visits, crude OR 3.73 (3.14 to 4.42$))$. $^{21}$

\section{Comorbid conditions and risk of CAP}

The association between comorbidities and the risk of CAP was investigated in 14 case-control studies (Denmark $(n=1),{ }^{48}$ Germany $(n=1),{ }^{44}$ The Netherlands $(n=1),{ }^{23}$ Spain $(n=2)^{12} 38$ and the UK $(n=9)^{14} 19-2242464749$ (see online supplementary table S4).

A history of respiratory disease was associated with an increased risk of CAP. A history of pneumonia increased the risk of a subsequent episode (crude ORs: 2.39 to 6.25 (1.83 to $\left.21.40)^{22} 38{ }^{44}\right)$. Patients with chronic respiratory diseases, including COPD, bronchitis or asthma, had a twofold to fourfold increase in the risk of CAP (crude ORs: 2.17 (1.99 to 2.37) to $3.92(3.67 \text { to } 4.18)^{12} 14 \quad 21-2338444647$ ). Additional data also support this association. One study reported an adjusted OR of 2.47 (2.37 to 2.58 ) for chronic respiratory disease, ${ }^{20}$ and another study reported adjusted RRs of 2.82 (2.45 to 3.24$)$ for COPD and 1.58 (1.44 to 1.74 ) for asthma. ${ }^{42}$ Patients with at least one respiratory tract infection in the past year were also at increased risk of CAP (crude ORs: 1.57 (1.35 to 1.84$)^{38}$ to 4.5 $\left.(3.7 \text { to } 5.4)^{44}\right)$. In young adults, the risk of CAP increased in line with the number of infections over the previous 6 years (12 infections, adjusted OR 1.49 (0.87 to 2.56); >3 infections, adjusted OR $4.84(1.24$ to 18.9$)) .^{23}$

Chronic cardiovascular disease increased the risk of CAP up to threefold (crude ORs from 1.4 (1.2 to 1.5 ) to 3.2 (2.6 to $4.1)^{12} 21223844464749$ ). Additional studies supported an association between chronic heart disease (adjusted ORs: 1.63 (1.54 to 1.72$)^{46}$ and $1.66(1.59 \text { to } 1.73)^{20}$ ) or heart failure (adjusted ORs: $2.19(0.69 \text { to } 6.95)^{12}$ and $1.37(1.20 \text { to } 1.57)^{19}$; adjusted RR: 2.63 (2.21 to 3.14$)^{42}$ ) and the risk of CAP.

Cerebrovascular disease/stroke and dementia approximately doubled the risk of CAP (for cerebrovascular disease/stroke, crude ORs: 1.86 (1.74 to 1.99 ) to 2.37 (2.19 to 2.57$),{ }^{14} 214649$ adjusted ORs: $1.08(0.93 \text { to } 1.26)^{19}$ and 1.68 (1.58 to 1.77$){ }^{20}$ adjusted RR: $1.42(1.25 \text { to } 1.61)^{42}$ for dementia, crude ORs: 2.12 (0.91 to 4.94$)$ to 2.41 (2.11 to 2.75$),{ }^{14} 3846$ adjusted ORs: $2.64(1.86 \text { to } 3.75)^{19}$ and $\left.2.68(2.42 \text { to } 2.97)^{20}\right)$. Other neurological or psychiatric conditions were also associated with an 
increased risk of CAP in some studies (epilepsy, crude ORs: 2.81 (1.83 to 4.30 ) and 2.83 (1.11 to 7.21$)^{2138}$; Parkinson's disease, crude ORs: 1.82 (1.52 to 2.19$)$ and $1.87(1.60 \text { to } 2.19)^{14}{ }^{46}$; multiple sclerosis, crude OR $\left.3.20(2.40 \text { to } 4.26)^{46}\right)$. Crude ORs for CAP in patients with depression or bipolar disorder ranged from 1.75 (1.65 to 1.86 ) to 2.54 (1.03 to 6.26$){ }^{1421}{ }^{23}$ However, the association with depression may have been confounded by other factors, as other studies reported an adjusted OR of 1.13 (0.99 to 1.28$)^{19}$ or an adjusted RR of 1.30 (1.19 to 1.40$){ }^{42}$

Two studies in elderly patients found a strong association between dysphagia and risk of CAP. A large database study in patients aged $\geq 65$ years reported a crude OR of 2.10 (1.85 to $2.38),{ }^{14}$ whereas a small study in patients aged $\geq 70$ years reported a crude OR of 16.3 (4.57 to 58.2) and an adjusted OR of 11.9 (3.03 to 46.9$).^{12}$

Data from several studies suggested that diabetes mellitus was associated with a moderate increase in the risk of CAP (crude ORs: 1.43 (1.11 to 1.92 ) to 1.54 (1.44 to 1.65$),{ }^{2138} 46$ adjusted ORs: 1.07 (0.89 to 1.28$)^{19}$ and 1.33 (1.26 to 1.41$){ }^{20}$ adjusted RRs: $1.26(1.21 \text { to } 1.31)^{48}$ and 1.28 (1.13 to 1.44$\left.)^{42}\right)$.

Cancer was also associated with a moderate increase in the risk of CAP (crude ORs: $1.42(1.04 \text { to } 1.92)^{38}$ and 1.70 (1.58 to 1.82$){ }^{46}$ adjusted ORs: $1.42(1.3 \text { to } 1.56)^{46}$ and 1.36 (1.24 to $1.49),{ }^{20}$ adjusted RR: $\left.1.37(1.22 \text { to } 1.54)^{42}\right)$. One study reported a fivefold higher risk in patients with lung cancer (crude OR: 4.73 (3.58 to 6.25$)$ ). ${ }^{46}$

Chronic liver or renal disease increased the risk of CAP approximately twofold (chronic liver disease, crude ORs: 1.67 (0.99 to 2.82 ) to 2.24 (1.74 to 2.89$), 384446$ adjusted ORs: 1.87 $(1.43 \text { to } 2.44)^{46}$ and $1.85(1.48 \text { to } 2.31)^{20}$; chronic renal disease, crude ORs: 1.7 (1.1 to 2.8$)^{44}$ and 2.15 (1.81 to 2.56$){ }^{46}$ adjusted ORs: $1.72(1.43 \text { to } 2.07)^{46}$ and $\left.1.78(1.53 \text { to } 2.07)^{20}\right)$.

Associations between conditions affecting immune function and the risk of CAP were reported. There was a moderate increase in risk in patients with rheumatoid arthritis (crude ORs: $1.46(1.14 \text { to } 1.88)^{21}$ and 2.02 (1.79 to 2.29$),{ }^{46}$ adjusted ORs: 1.84 (1.62 to 2.10$)^{46}$ and 1.83 (1.64 to 2.03$),{ }^{20}$ adjusted RR: $\left.1.37(1.12 \text { to } 1.69)^{42}\right)$. Additionally, there was over a twofold increase in risk in patients with asplenia (adjusted OR: $\left.2.58(1.80 \text { to } 3.71)^{46}\right)$ or with HIV or AIDS (adjusted ORs: $2.48(1.34 \text { to } 4.58)^{46}$ and $\left.5.90(2.55 \text { to } 13.64)^{20}\right)$.

In addition to the above medical conditions, a moderate increase in risk of CAP was reported in patients with anaemia (adjusted RR: 1.43 (1.25 to 1.62$)$ ). ${ }^{42}$

Hospitalisation in the previous 5 years was associated with an increased risk of CAP (crude ORs: $1.6(1.4 \text { to } 1.9)^{44}$ and 1.68 $\left.(1.44 \text { to } 1.96)^{38}\right)$. An adjusted RR of 1.77 (1.59 to 1.97$)$ was calculated in patients with more than one hospitalisation in the previous year. ${ }^{42}$ The risk of CAP was increased in patients who had undergone either bronchoscopy (crude OR: 2.09 (1.07 to 4.06)) or passage of a nasogastric tube (crude OR: 3.21 (1.17 to 8.77)) during the previous year. ${ }^{38}$

\section{Comorbid conditions in patients with CAP}

The frequency of comorbidities in patients diagnosed with CAP was presented in 39 studies $(7$ case-control studies of observational data, ${ }^{15} 194550-53$ and 31 observational, cohort studies ${ }^{10}$

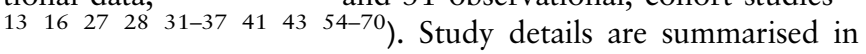
online supplementary table S5.

The most common comorbidities were chronic respiratory diseases (up to $68 \%$ of patients), chronic heart disease (up to $47 \%$ ) or heart failure (up to $46 \%$ ), diabetes mellitus, cerebrovascular diseases and dementia (all up to 33\%; table 3). Chronic liver and chronic renal diseases were observed in up to $20 \%$ and
Table 3 Frequency of comorbid conditions in adults with community-acquired pneumonia

\begin{tabular}{llc}
\hline Comorbid condition & $\begin{array}{l}\text { Number of cohorts } \\
\text { with data* }\end{array}$ & $\begin{array}{c}\text { Patients with } \\
\text { condition (\%) }\end{array}$ \\
\hline $\begin{array}{l}\text { Previous pneumonia } \\
\text { Chronic respiratory }\end{array}$ & 10 & $3.2-33.8$ \\
disease & 25 & $9.7-68$ \\
$\quad$ COPD & 21 & $9.4-62$ \\
$\quad$ Asthma & 9 & $3-50.0$ \\
Chronic heart disease & 23 & $10-47.2$ \\
$\quad$ Heart failure & 27 & $1.0-46$ \\
Diabetes mellitus & 48 & $4.9-33.0$ \\
Cerebrovascular disease/ & 26 & $3.2-33$ \\
stroke & 12 & $1.1-33.6$ \\
Dementia & 33 & $4.3-18.0$ \\
Cancer & 36 & $0.3-20$ \\
Chronic liver disease & 39 & $0.5-26.7$ \\
Chronic renal disease & 39 & \\
\hline *For studies that only reported data separately for each cohort, all cohorts were \\
included; for studies that reported data for the overall study population, the summary \\
data were used. \\
COPD, chronic obstructive pulmonary disease.
\end{tabular}

$27 \%$ of patients, respectively. The frequency of comorbidities was generally higher in patients aged $\geq 65$ years compared with those aged $<65$ years, and in patients with COPD, chronic renal failure or cirrhosis compared with those without such conditions (see online supplementary table S5).

\section{DISCUSSION}

This review represents a comprehensive compilation of data about the incidence of and risk factors for CAP in adults in Western Europe.

Notwithstanding the heterogeneity of the populations studied and measures of incidence rates used, overall the annual incidence was $1.07-1.7$ per 1000 population. Studies consistently showed that the incidence was higher in men than in women, and that it increased with age; in patients aged $\geq 65$ years, an incidence rate of 14 cases per 1000 person-years was reported. ${ }^{16}$ These findings are consistent with those of a recent review of European incidence rates published between 1990 and 2007. ${ }^{1}$ Also in line with previous studies of CAP epidemiology, incidence rates were higher in patients with comorbidities such as COPD, ${ }^{8}$ and in patients with HIV compared with those without HIV. ${ }^{71}$ Possible explanations for the higher rates of hospitalisation for CAP compared with overall incidence rates include the inclusion of data from different countries (Italy, ${ }^{37}$ Spain $^{38}{ }^{43}$ and the UK ${ }^{42}$ for overall incidence rates; Denmark, ${ }^{17}$ 18 Germany $^{36}$ and the $\mathrm{UK}^{41}$ for hospitalisation) reflecting national differences in medical practice, and that Danish studies were performed in patients aged $>50$ years, ${ }^{17}{ }^{18}$ and so represent a population at increased risk of CAP. ${ }^{12}$

Importantly, this review included data obtained from observational and case-control studies. While observational studies provide valuable data on the rates of comorbidities observed in patients with CAP, they do not permit their identification as risk factors for infection. However, case-control studies of patients allow us to establish which comorbidities are indeed risk factors for CAP.

Pooled data from observational studies demonstrated the overall burden of CAP in patients with other medical conditions. ${ }^{10} 1316272831-37414354-70$ Chronic respiratory diseases, 
cardiovascular diseases, cerebrovascular diseases, dementia and diabetes mellitus were the most frequently observed comorbidities. Up to two-thirds of patients had a chronic respiratory disease and almost half had a chronic cardiovascular disease, highlighting the need for appropriate management of these patients to reduce their risk of CAP.

Lifestyle factors such as smoking, high alcohol intake, being underweight, living in a large household or having regular contact with children were associated with an increased risk of CAP. $^{12}{ }^{19-23} \quad 30 \quad 3842444647$ Smoking is an established risk factor for CAP, ${ }^{6}{ }^{72}$ probably due to its adverse effects on the respiratory epithelium and the clearance of bacteria from the respiratory tract. ${ }^{73}$ Alcoholism has been associated with defects in innate and adaptive immunity, ${ }^{74}$ and is a recognised CAP risk factor. ${ }^{7}$ Smoking and excessive alcohol consumption are major health risks globally and are targets for interventions to reduce the global burden of disease. ${ }^{75}$ Ensuring that patients make appropriate lifestyle changes would help to reduce the overall burden of CAP. Being underweight may predispose patients to CAP due to the consequences of undernutrition or underlying conditions on immune function. ${ }^{6}{ }^{44} 7276$ Assessment of the nutritional status of vulnerable patients might help to identify those at increased risk of CAP. Regular contact with children has also been identified previously as a risk factor for CAP, possibly due to the high carriage of Streptococcus pneumoniae by children. ${ }^{44} 77$ Appropriate measures for infection control may be advisable in vulnerable patients who are in regular contact with children.

Some lifestyle factors may provide protection against CAP. Young adults who consumed $<40 \mathrm{~g}$ of alcohol per day had a lower risk of CAP than those who drank no alcohol, ${ }^{23}$ potentially because individuals who consumed no alcohol had other comorbidities that increased the risk of CAP. However, light-to-moderate alcohol intake has been reported to reduce the risk of atherosclerosis and cardiovascular disease, ${ }^{78} 79$ due to the antioxidant activities of alcohol, ${ }^{78}$ and this may also protect against CAP. Adherence to good dental hygiene was also associated with a reduced risk of CAP. Poor oral care has previously been identified as a risk factor for nursing-home acquired pneumonia, possibly due to the colonisation of the oral cavity by respiratory pathogens, ${ }^{80}$ and this risk may also be relevant for CAP. Finally, a higher level of education appeared to reduce the risk of CAP compared with a low level of education, as reported previously for invasive pneumococcal disease. ${ }^{81} \mathrm{~A}$ similar protective association of higher educational levels has also been described in relation to cardiovascular risk factors. ${ }^{82}$
Measures to reduce social and health inequalities could have the benefit of reducing costs associated with diseases like CAP.

The review also provides robust evidence that several comorbidities are associated with an increased risk of CAP, including a history of respiratory disease (including pneumonia) and cardiovascular disease. Patients with COPD are recognised as having a high risk of $\mathrm{CAP}^{8}$ and are targets for vaccination against influenza and pneumococcal disease, ${ }^{83} 84$ as are patients with chronic cardiovascular diseases. ${ }^{84-86}$

Patients with cerebrovascular disease or stroke, and neurological disorders (dementia, epilepsy, Parkinson's disease and multiple sclerosis) had approximately twice the risk of CAP compared with individuals without these conditions; dysphagia was also associated with a substantial increase in risk. The use of sedative medications and problems with swallowing might contribute to the risk of CAP in patients with dementia, ${ }^{19} 43$ probably due to aspiration and its associated risk of pneumonia. ${ }^{87}$ This could apply to patients with other neurological disorders.

Other comorbid conditions associated with an increased risk of CAP in the present study, including diabetes mellitus, cancer, chronic liver or renal disease, and impaired immune function, have previously been identified as risk factors for CAP. ${ }^{9}$

The main strength of this review is that many of the included publications were of case-control studies performed in large numbers of patients from registries or primary care databases, rather than small, single-centre studies, providing reassurance that the included studies provide a good representation of CAP in European populations.

This review also has some limitations. Patient registries and primary care databases are dependent on the quality of the information included in the records, and rely on the accuracy of the individuals responsible for entering diagnostic codes and demographic data. However, the inclusion of several thousand patients in such studies should help to minimise any potential introduced bias. Most of the included studies were based on patient populations in either Spain (23 studies ${ }^{10} 121316253233$ $35 \quad 38-40 \quad 43 \quad 50 \quad 54-5963 \quad 656869$ ) or the UK (12 studies ${ }^{14} 19-2241$ 424647495366 ), and this could limit the validity of the review for extrapolating the data to other European populations. Only those studies that were indexed in the PubMed database were included, and data from, for example, national surveillance databases were not included. Nevertheless, we believe it provides a good representation of the incidence and risk factors for CAP in European countries.

Lifestyle interventions, such as stopping smoking, reducing alcohol consumption, having regular dental checks and

Table 4 Bundles for lifestyle interventions to reduce the risk of CAP in adults

\begin{tabular}{|c|c|c|}
\hline Risk factor & Evidence & Recommendation \\
\hline Smoking & $\begin{array}{l}\text { Risk of CAP increased in current and former } \\
\text { smokers ( } 9 \text { studies) }{ }^{19-23} 38424647\end{array}$ & Smoking cessation \\
\hline Alcohol consumption & $\begin{array}{l}\text { Risk of CAP increased with high consumption or history of alcohol } \\
\text { abuse ( } 4 \text { studies) } 21233847\end{array}$ & Reduce alcohol consumption \\
\hline Nutritional status & $\begin{array}{l}\text { Being underweight was generally associated with an increased risk of } \\
\text { CAP (4 studies) }{ }^{23} 384447\end{array}$ & Dietary advice to ensure good nutritional status \\
\hline Contact with children & $\begin{array}{l}\text { Regular contact with children increased the risk of CAP ( } 3 \\
\text { studies) })^{23} 3844\end{array}$ & $\begin{array}{l}\text { Avoid contacts with children with lower respiratory } \\
\text { tract infections }\end{array}$ \\
\hline Dental hygiene & $\begin{array}{l}\text { Risk of CAP decreased in individuals with a recent (within past year) } \\
\text { dental visit ( } 2 \text { studies) })^{23} 38\end{array}$ & Ensure regular dental visits \\
\hline $\begin{array}{l}\text { Vaccination against influenza and } \\
\text { Streptococcus pneumoniae }\end{array}$ & Current guidelines 8889 & Ensure compliance with guidelines \\
\hline
\end{tabular}


maintaining good nutritional status could help to reduce the burden of CAP. Patients with conditions such as chronic respiratory, cardiovascular and neurological diseases should be managed in accordance with current clinical guidelines to optimise their overall health status, and elderly patients should try to minimise contact with children who have acute viral respiratory infections. Finally, adults at risk of CAP should be vaccinated against influenza and pneumococcal pneumonia to reduce the risk of lower respiratory tract infections, in accordance with current guidelines (table 4). ${ }^{88} 89$

All but six of the studies included patients with pneumonia of any aetiology. $S$ pneumoniae is the most frequently isolated pathogen from patients with CAP in Europe, ${ }^{1}$ and has been estimated to be the cause of $30-50 \%$ cases of CAP requiring hospitalisation in adults in developed countries. ${ }^{90}$ A 23 -valent pneumococcal polysaccharide vaccine is recommended in some countries for the routine vaccination of adults aged $\geq 65$ years, and for patients at increased risk of CAP. ${ }^{85}{ }^{86}$ However, there is little evidence that it is effective in elderly people or adults with chronic diseases. ${ }^{91} 92$ A 13 -valent pneumococcal conjugate vaccine (PCV-13) is available for the prevention of pneumonia and invasive pneumococcal disease caused by PCV-13 serotypes in adults aged $\geq 18$ years. ${ }^{93}$ Efficacy of PCV-13 for the prevention of a first episode of vaccine serotype-specific pneumococcal CAP in community-dwelling adults aged $\geq 65$ years is being investigated in the ongoing Community Acquired Pneumonia Immunisation Trial in Adults. ${ }^{94}$

In conclusion, this review of risk factors for CAP in European adults has highlighted the range of lifestyle factors and underlying medical conditions that are associated with an increased risk of infection. Lifestyle factors included smoking, alcohol abuse, being underweight and regular contact with children, whereas patients with chronic respiratory or cardiovascular diseases, cerebrovascular disease, epilepsy, dementia, dysphagia, HIV, or chronic renal or liver disease were all at increased risk of CAP. Greater understanding of the types of individuals at risk of CAP can help to ensure that interventions to reduce the risk of infection and burden of disease are targeted appropriately.

Acknowledgements The authors take full responsibility for the content of this article and thank Neostar Communications Limited, Oxford, UK (supported by Pfizer, France), for their assistance in preparing the manuscript, including preparing the first draft in close collaboration with the authors and the collation of author comments.

Contributors AT, WEP, GV and FB approved the literature search, commented on drafts of the manuscript and approved the final draft. AT is guarantor. Nathalie Dartois (Pfizer Ltd, Paris, France) discussed the manuscript concept with AT and reviewed drafts of the manuscript. Neostar Communications collaborated closely with the authors throughout the development of the manuscript and were responsible for performing the literature search, preparing the first draft of the article and providing author comments.

Funding Pfizer supported Neostar Communications for preparation of the manuscript in close collaboration with the authors.

Competing interests AT has received consulting fees/honorarium from Astra-Zeneca, Bayer, Curetis, GlaxoSmithKline, Pfizer and Polyphor. WEP has received consulting fees/honorarium from Pfizer; fees for board membership from Astellas, AstraZeneca, Bayer, GlaxoSmithKline Biologicals, Merck-Shering and Pfizer; and his institution has received research grants for investigator-initiated research from AstraZeneca, Bayer, Pfizer and Sanofi-Aventis. GV's institution has received consulting fees/honorarium from Pfizer. FB has received financial support for travel to meetings from Pfizer; consultancy fees from AstraZeneca, Pfizer and Zambon; fees for board membership from AstraZeneca, Chiesi, GlaxoSmithKline, Novartis and Pfizer; lecture fees/speaker bureaus fees from AstraZeneca, Chiesi, Novartis, Pfizer and Zambon; and his institution has received grants from Chiesi, Novartis, Pfizer and Zambon.

Provenance and peer review Not commissioned; internally peer reviewed.

Open Access This is an Open Access article distributed in accordance with the Creative Commons Attribution Non Commercial (CC BY-NC 3.0) license, which permits others to distribute, remix, adapt, build upon this work non-commercially, and license their derivative works on different terms, provided the original work is properly cited and the use is non-commercial. See: http://creativecommons.org/ licenses/by-nc/3.0/

\section{REFERENCES}

1 Welte T, Torres A, Nathwani D. Clinical and economic burden of community-acquired pneumonia among adults in Europe. Thorax 2012;67:71-9.

2 Blasi F, Mantero M, Santus $P$, et al. Understanding the burden of pneumococcal disease in adults. Clin Microbiol Infect 2012;18:1-8.

3 Lozano R, Naghavi M, Foreman K, et al. Global and regional mortality from 235 causes of death for 20 age groups in 1990 and 2010: a systematic analysis for the Global Burden of Disease Study 2010. Lancet 2012;380:2095-128.

4 European Commission. Health statistics. Atlas on mortality in the European Union. Luxembourg: Office for Official Publications of the European Communities, 2008.

5 Pneumonia. In: European lung white book. 2nd edn. Sheffield, UK: European Respiratory Society/European Lung Foundation, 2003:55-65.

6 Baik I, Curhan GC, Rimm EB, et al. A prospective study of age and lifestyle factors in relation to community-acquired pneumonia in US men and women. Arch Intern Med 2000;160:3082-8.

7 Koivalu I, Sten M, Makela PH. Risk factors for pneumonia in the elderly. Am J Med 1994;96:313-20.

8 Mannino DM, Davis KJ, Kiri VA. Chronic obstructive pulmonary disease and hospitalizations for pneumonia in a US cohort. Respir Med 2009;103:224-9.

9 Polverino E, Torres Marti A. Community-acquired pneumonia. Minerva Anestesiol 2011;77:196-211.

10 de Roux A, Cavalcanti M, Marcos MA, et al. Impact of alcohol abuse in the etiology and severity of community-acquired pneumonia. Chest 2006;129:1219-25.

11 Jover F, Cuadrado JM, Andreu L, et al. A comparative study of bacteremic and non-bacteremic pneumococcal pneumonia. Eur J Intern Med 2008;19:15-21.

12 Almirall J, Rofes L, Serra-Prat $M$, et al. Oropharyngeal dysphagia is a risk factor for community-acquired pneumonia in the elderly. Eur Respir J 2013;41:923-8.

13 Cabre M, Serra-Prat M, Palomera E, et al. Prevalence and prognostic implications of dysphagia in elderly patients with pneumonia. Age Ageing 2010;39:39-45.

14 Hennessy S, Bilker WB, Leonard CE, et al. Observed association between antidepressant use and pneumonia risk was confounded by comorbidity measures. J Clin Epidemiol 2007:60:911-18.

15 Trifiro G, Gambassi G, Sen EF, et al. Association of community-acquired pneumonia with antipsychotic drug use in elderly patients: a nested case-control study. Ann Intern Med 2010;152:418-40.

16 Vila-Corcoles A, Ochoa-Gondar 0, Rodriguez-Blanco T, et al. Epidemiology of community-acquired pneumonia in older adults: a population-based study. Respir Med 2009;103:309-16.

17 Kornum JB, Norgaard M, Dethlefsen C, et al. Obesity and risk of subsequent hospitalisation with pneumonia. Eur Respir J 2010:36:1330-6.

18 Kornum JB, Due KM, Norgaard M, et al. Alcohol drinking and risk of subsequent hospitalisation with pneumonia. Eur Respir J 2012;39:149-55.

19 Mullerova $\mathrm{H}$, Chigbo C, Hagan GW, et al. The natural history of community-acquired pneumonia in COPD patients: A population database analysis. Respir Med 2012;106:1124-33.

20 Vinogradova Y, Coupland C, Hippisley-Cox J. Risk of pneumonia in patients taking statins: population-based nested case-control study. Br J Gen Pract 2011;61: e742-8.

21 Schlienger RG, Fedson DS, Jick SS, et al. Statins and the risk of pneumonia: a population-based, nested case-control study. Pharmacotherapy 2007;27:325-32.

22 Myles PR, Hubbard RB, McKeever TM, et al. Risk of community-acquired pneumonia and the use of statins, ace inhibitors and gastric acid suppressants: a population-based case-control study. Pharmacoepidemiol Drug Saf 2009;18:269-75.

23 Teepe J, Grigoryan L, Verheij TJ. Determinants of community-acquired pneumonia in children and young adults in primary care. Eur Respir J 2010:35:1113-17.

24 Benard A, Mercie P, Alioum A, et al. Bacterial pneumonia among HIV-infected patients: decreased risk after tobacco smoking cessation. ANRS CO3 Aquitaine Cohort, 2000-2007. PLOS ONE 2010;5:e8896.

25 Curran A, Falco V, Crespo M, et al. Bacterial pneumonia in HIV-infected patients: use of the pneumonia severity index and impact of current management on incidence, aetiology and outcome. HIV Med 2008;9:609-15.

26 Le Moing V, Rabaud C, Journot $V$, et al. Incidence and risk factors of bacterial pneumonia requiring hospitalization in HIV-infected patients started on a protease inhibitor-containing regimen. HIV Med 2006;7:261-7.

27 Madeddu G, Porqueddu EM, Cambosu F, et al. Bacterial community acquired pneumonia in HIV-infected inpatients in the highly active antiretroviral therapy era. Infection 2008;36:231-6

28 Manno D, Puoti M, Signorini L, et al. Risk factors and clinical characteristics associated with hospitalization for community-acquired bacterial pneumonia in HIV-positive patients according to the presence of liver cirrhosis. Infection 2009;37:334-9. 
29 Saindou M, Chidiac C, Miailhes $\mathrm{P}$, et al. Pneumococcal pneumonia in HIV-infected patients by antiretroviral therapy periods. HIV Med 2008;9:203-7.

30 Che D, Campese C, Santa-Olalla P, et al. Sporadic community-acquired Legionnaires' disease in France: a 2-year national matched case-control study. Epidemiol Infect 2008;136:1684-90.

31 Chidiac C, Che D, Pires-Cronenberger S, et al. Factors associated with hospital mortality in community-acquired legionellosis in France. Eur Respir 2012;39:963-70.

32 Sopena N, Force L, Pedro-Botet ML, et al. Sporadic and epidemic community legionellosis: two faces of the same illness. Eur Respir J 2007;29:138-42.

33 Sopena N, Pedro-Botet L, Mateu L, et al. Community-acquired legionella pneumonia in elderly patients: characteristics and outcome. J Am Geriatr Soc 2007;55: 114-19

34 Kofteridis D, Samonis G, Mantadakis E, et al. Lower respiratory tract infections caused by Haemophilus influenzae: clinical features and predictors of outcome. Med Sci Monit 2009:15:CR135-39.

35 Ruiz LA, Gomez A, Jaca C, et al. Bacteraemic community-acquired pneumonia due to Gram-negative bacteria: incidence, clinical presentation and factors associated with severity during hospital stay. Infection 2010;38:453-8.

36 Ewig S, Birkner N, Strauss R, et al. New perspectives on community-acquired pneumonia in 388406 patients. Results from a nationwide mandatory performance measurement programme in healthcare quality. Thorax 2009;64:1062-9.

37 Viegi G, Pistelli R, Cazzola M, et al. Epidemiological survey on incidence and treatment of community acquired pneumonia in Italy. Respir Med 2006;100:46-55

38 Almirall J, Bolibar I, Serra-Prat M, et al. New evidence of risk factors for community-acquired pneumonia: a population-based study. Eur Respir J 2008;31:1274-84.

39 Gutierrez F, Masia M, Mirete C, et al. The influence of age and gender on the population-based incidence of community-acquired pneumonia caused by different microbial pathogens. J Infect 2006:53:166-74

40 Perez-Sola MJ, Torre-Cisneros J, Perez-Zafrilla B, et al. Infections in patients treated with tumor necrosis factor antagonists: incidence, etiology and mortality in the BIOBADASER registry. Med Clin (Barc) 2011;137:533-40.

41 Bewick T, Sheppard C, Greenwood S, et al. Serotype prevalence in adults hospitalised with pneumococcal non-invasive community-acquired pneumonia. Thorax 2012:67:540-5.

42 Rodriguez LA, Ruigomez A, Wallander MA, et al. Acid-suppressive drugs and community-acquired pneumonia. Epidemiology 2009;20:800-6.

43 Gutierrez F, Masia M, Rodriguez JC, et al. Epidemiology of community-acquired pneumonia in adult patients at the dawn of the 21st century: a prospective study on the Mediterranean coast of Spain. Clin Microbiol Infect 2005;11:788-800.

44 Schnoor M, Klante T, Beckmann M, et al. Risk factors for community-acquired pneumonia in German adults: the impact of children in the household. Epidemio Infect 2007;135:1389-97

45 van de Garde EM, Souverein PC, van den Bosch JM, et al. Angiotensin-converting enzyme inhibitor use and pneumonia risk in a general population. Eur Respir J 2006;27:1217-22

46 Vinogradova Y, Hippisley-Cox J, Coupland C. Identification of new risk factors for pneumonia: population-based case-control study. Br J Gen Pract 2009;59:e329-38.

47 van de Garde EM, Hak E, Souverein PC, et al. Statin treatment and reduced risk of pneumonia in patients with diabetes. Thorax 2006;61:957-61.

48 Kornum JB, Thomsen RW, Riis A, et al. Diabetes, glycemic control, and risk of hospitalization with pneumonia: a population-based case-control study. Diabetes Care 2008:31:1541-5.

49 van de Garde EM, Souverein PC, Hak E, et al. Angiotensin-converting enzyme inhibitor use and protection against pneumonia in patients with diabetes. J Hypertens 2007;25:235-9.

50 Almirall J, Bolibar I, Serra-Prat M, et al. Inhaled drugs as risk factors for community-acquired pneumonia. Eur Respir J 2010;36:1080-7.

51 Gulmez SE, Holm A, Frederiksen $\mathrm{H}$, et al. Use of proton pump inhibitors and the risk of community-acquired pneumonia: a population-based case-control study. Arch Intern Med 2007;167:950-5.

52 Nielsen AG, Nielsen RB, Riis AH, et al. The impact of statin use on pneumonia risk and outcome: a combined population-based case-control and cohort study. Crit Care 2012;16:R122.

53 Sarkar M, Hennessy S, Yang YX. Proton-pump inhibitor use and the risk for community-acquired pneumonia. Ann Intern Med 2008;149:391-8.

54 Carratala J, Mykietiuk A, Fernandez-Sabe N, et al. Health care-associated pneumonia requiring hospital admission: epidemiology, antibiotic therapy, and clinical outcomes. Arch Intern Med 2007:167:1393-9.

55 Cilloniz C, Ewig S, Ferrer $\mathrm{M}$, et al. Community-acquired polymicrobial pneumonia in the intensive care unit: aetiology and prognosis. Crit Care 2011;15:R209.

56 Cilloniz C, Ewig S, Polverino E, et al. Pulmonary complications of pneumococcal community-acquired pneumonia: incidence, predictors, and outcomes. Clin Microbiol Infect 2012;18:1134-42.

57 Falguera M, Carratala J, Ruiz-Gonzalez A, et al. Risk factors and outcome of community-acquired pneumonia due to Gram-negative bacilli. Respirology 2009:14:105-11.
58 Garcia-Vidal C, Carratala J, Fernandez-Sabe N, et al. Aetiology of, and risk factors for, recurrent community-acquired pneumonia. Clin Microbiol Infect 2009;15:1033-8

59 Giannella M, Pinilla B, Capdevila JA, et al. Pneumonia treated in the internal medicine department: focus on healthcare-associated pneumonia. Clin Microbiol Infect 2012;18:786-94.

60 Holm A, Nexoe J, Bistrup LA, et al. Aetiology and prediction of pneumonia in lower respiratory tract infection in primary care. Br J Gen Pract 2007;57:547-54.

61 Klapdor B, Ewig S, Pletz MW, et al. Community-acquired pneumonia in younger patients is an entity on its own. Eur Respir J 2012:39:1156-61.

62 Kothe $H$, Bauer T, Marre R, et al. Outcome of community-acquired pneumonia: influence of age, residence status and antimicrobial treatment. Eur Respir $\mathrm{J}$ 2008;32:139-46.

63 Liapikou A, Polverino E, Ewig S, et al. Severity and outcomes of hospitalised community-acquired pneumonia in COPD patients. Eur Respir J 2012;39:855-61.

64 Migliorati PL, Boccoli E, Bracci LS, et al. A survey on hospitalised community-acquired pneumonia in Italy. Monaldi Arch Chest Dis 2006;65:82-8.

65 Molinos L, Clemente MG, Miranda B, et al. Community-acquired pneumonia in patients with and without chronic obstructive pulmonary disease. J Infect 2009;58:417-24.

66 Myint PK, Lowe D, Stone RA, et al. U.K. National COPD Resources and Outcomes Project 2008: patients with chronic obstructive pulmonary disease exacerbations who present with radiological pneumonia have worse outcome compared to those with non-pneumonic chronic obstructive pulmonary disease exacerbations. Respiration 2011:82:320-7.

67 Thomsen RW, Riis A, Kornum JB, et al. Preadmission use of statins and outcomes after hospitalization with pneumonia: population-based cohort study of 29,900 patients. Arch Intern Med 2008;168:2081-7.

68 Viasus D, Garcia-Vidal C, Cruzado JM, et al. Epidemiology, clinical features and outcomes of pneumonia in patients with chronic kidney disease. Nephrol Dial Transplant 2011;26:2899-906

69 Viasus D, Garcia-Vidal C, Castellote J, et al. Community-acquired pneumonia in patients with liver cirrhosis: clinical features, outcomes, and usefulness of severity scores. Medicine (Baltimore) 2011:90:110-18.

70 von Baum H, Welte T, Marre R, et al. Community-acquired pneumonia through Enterobacteriaceae and Pseudomonas aeruginosa: diagnosis, incidence and predictors. Eur Respir J 2010;35:598-605.

71 Sogaard OS, Lohse N, Gerstoft J, et al. Hospitalization for pneumonia among individuals with and without HIV infection, 1995-2007: a Danish population-based, nationwide cohort study. Clin Infect Dis 2008;47:1345-53.

72 Almirall J, Gonzalez CA, Balanzó X, et al. Proportion of community-acquired pneumonia cases attributable to tobacco smoking. Chest 1999;116:375-9.

73 Dye JA, Adler KB. Effects of cigarette smoke on epithelial cells of the respiratory tract. Thorax 1994;49:825-34.

74 Nelson S, Kolls JK. Alcohol, host defence and society. Nat Rev Immunol 2002;2:205-9.

75 World Health Organization. The World health Report 2002. Reducing risks, promoting healthy life. Geneva, Switzerland: World Health Organization, 2002.

76 Hedlund J, Hansson LO, Ortqvist A. Short- and long-term prognosis for middle-aged and elderly patients hospitalised with community-acquired pneumonia: impact of nutritional and inflammatory factors. Scand J Infect Dis 1995;27:32-7.

77 Hendley JO, Sande MA, Stewart PM, et al. Spread of Streptococcus pneumoniae in families. I. Carriage rates and distribution of types. J Infect Dis 1975;132:55-61.

78 Arranz S, Chiva-Blanch G, Valderas-Martínez P, et al. Wine, beer, alcohol and polyphenols on cardiovascular disease and cancer. Nutrients 2012;4:759-81.

79 Ronksley PE, Brien SE, Turner BJ, et al. Association of alcohol consumption with selected cardiovascular disease outcomes: a systematic review and meta-analysis. BMJ 2011:342:d671.

80 Quagliarello V, Ginter S, Han L, et al. Modifiable risk factors for nursing home-acquired pneumonia. Clin Infect Dis 2005:40:1-6

81 Nuorti JP, Butler JC, Farley MM, et al. Cigarette smoking and invasive pneumococcal disease. N Engl J Med 2000;342:681-9.

82 Winkleby MA, Jatulis DE, Frank $E$, et al. Socioeconomic status and health: how education, income, and occupation contribute to risk factors for cardiovascular disease. Socioeconomic status and health: how education, income, and occupation contribute to risk factors for cardiovascular disease. Am J Public Health 1992:82:816-20

83 Gaillat J. Should patients with chronic obstructive pulmonary disease be vaccinated against pneumococcal diseases? Expert Rev Respir Med 2009;3:585-96.

84 World Health Organization. Vaccines against influenza. WHO position paper-November 2012. Wkly Epidemiol Rec 2012;87:461-76

85 World Health Organization. 23-valent pneumococcal polysaccharide vaccine. WHO position paper. Wkly Epidemiol Rec 2008;83:373-84.

86 Advisory Committee on Immunization Practices. Recommended adult immunization schedule: United States, 2009. Ann Intern Med 2009;150:40-4.

87 Loeb M, McGeer A, McArthur M, et al. Risk factors for pneumonia and other lower respiratory tract infections in elderly residents of long-term care facilities. JAMA 1999:159:2058-64. 
88 Mandell LA, Wunderink RG, Anzueto A, et al. Infectious Diseases Society of America/American Thoracic Society consensus guidelines on the management of community-acquired pneumonia in adults. Clin Infect Dis 2007;44:S27-72.

89 Woodhead M, Blasi F, Ewig S, et al. Guidelines for the management of adult lower respiratory tract infections. Eur Respir J 2005;26:1138-80.

90 World Health Organization. Pneumococcal vaccines. WHO position paper-2012. Wkly Epidemiol Rec 2012;87:129-44

91 Huss A, Scott P, Stuck AE, et al. Efficacy of pneumococcal vaccination in adults: a meta-analysis. CMAJ 2009;180:48-58.
92 Moberley S, Holden J, Tatham DP, et al. Vaccines for preventing pneumococcal infection in adults. Cochrane Database Syst Rev 2008;1:CD000422. doi:10.1002/ 14651858.CD000422.pub2.

93 European Medicines Agency. Prevenar 13. http://www.medicines.org.uk/emc/ medicine/22689/SPC/Prevenar+13+suspension+for+injection/ (accessed 29 Jul 2013)

94 Hak E, Grobbee DE, Sanders EA, et al. Rationale and design of CAPITA: a RCT of 13-valent conjugated pneumococcal vaccine efficacy among older adults. Neth J Med 2008;66:378. 